\title{
REVIEW ARTICLE: Ethnic Feminism: Beyond the Pseudo-Pluralists
}

\author{
Sherry Gorelick
}

Ethnicity and Women, edited by Winston A. Van Horne. Madison, WI: University of Wisconsin System American Ethnic Studies Coordinating Committee/Urban Corridor Consortium, 1986, 223 pp., $\$ 20.00 \mathrm{Hb}$, $\$ 10.95 \mathrm{~Pb}$.

The Varieties of Ethnic Experience: Kinship, Class, and Gender Among California Italian-Americans, by Micaela di Leonardo. Ithaca, NY: Cornell University Press, 1984,262 pp., $\$ 29.95 \mathrm{Hb}, \$ 9.95 \mathrm{~Pb}$.

For years scholars and media in unholy alliance have elaborated racial, ethnic and gender stereotypes and called them science. In Beyond the Melting Pot, Nathan Glazer and Daniel Patrick Moynihan (1963) set the framework for all later work on North American ethnicity. It was a book of enormous influence. It had a huge impact on the media and on popular thought.

The book was first published in 1963, just two years before Moynihan, as a member of President Lyndon Johnson's Cabinet, published his infamous 'Report on the Negro Family' blaming Black poverty on the emasculating power of women in 'the Black Matriarchy'. The seeds of the Moynihan Report can be found in Beyond the Melting Pot, both specifically in its treatment of Black people and generally in the centrality of the family as the major category explaining ethnic inequality. The officially sanctified stereotypes of the 'good' Italian and Jewish family are counterfoil to the 'bad' Black and Puerto Rican family. The one set of stereotypes is used against the other and both are used against women.

According to Glazer and Moynihan the melting pot ... did not happen' because the 'group-forming tendencies' of American life have transformed ethnic groups into a new social form, acting as interest 
groups in American political life (v, 291). Their book was therefore part of the ethnic ideology called 'cultural pluralism'. But it was a pseudopluralism, because although it celebrated American democracy for including diverse groups, it set up an ethnic derby which pitted one group against another and evaluated them on the degree to which their cultures permitted absorption into the 'mainstream', that is, the dominant culture. Ethnic culture allegedly shapes the family, which in turn determines the economic success or failure of the group. Like its kin, political pluralism (which asserted that cross-cutting interest groups ensure that in the US political system no one group or class holds sway), cultural pluralism masked the structure of power underlying racial, ethnic and class inequalities.

Ethnic women appeared only as mothers whose cultural behavior either helped or harmed the achievement of their sons. But the invisibility of women is not the biggest problem. We cannot iron the book and have women appear like some secret lemon-juice message. The whole paradigm is faulty: as in every other field, one cannot simply 'add women and stir'.

Among the problems of the Glazer/Moynihan legacy are its cultural determinism and its lack of understanding of the structure, history, and process of change of capitalism, patriarchy and racism as systems. That is, not only are women invisible; the political-economic structures of racial, ethnic, class, and gender subordination are also invisible. I want to use two recent books to show both the harmful weight of the Glazer/Moynihan legacy, and the possibilities of its transcendence.

Micaela di Leonardo's Varieties of Ethnic Experience challenges the entire Glazer/Moynihan framework of cultural determinism, sexism and ideological bias. Interviewing men and women of several generations, di Leonardo shows that Italian cultural values are not homogeneous. They change with time and, although they may, along with structural factors, channel people's options, cultural values are not fundamentally causal in Italian-American behaviour. On the contrary, ethnic culture and identity are themselves formed within an ethnic, racial and class system.

Di Leonardo traces the effects of historical changes in the need for labour, and regional differences in the structure of agriculture and industry, on Italian-American migration patterns, women's work, family structure and the various ways that Italian-Americans experience and express ethnicity, discrimination and feminism. Contrasting the economic fortunes of West Coast Italians with those on the East Coast, di Leonardo shows that Italian opportunities were shaped by the different industrial structures of the two regions, the different timing of immigration flows and different local racial and ethnic structures:

'Racial minorities were present in California in significant proportions and were relegated to the lowest-status occupations. Racism against them probably siphoned off some of the oppression experienced by Italians elsewhere in the United States (64)'. 
That is, racism as structure and ideology, as it affected both Italians and people of colour, determined their relative fortunes; their prosperity or poverty was not caused by their possession or lack of properly patriarchal families. As di Leonardo notes,

Ethnic identity in the United States today is popularly assumed to imply an adherence to tradition, and tradition encodes the ideal of the patriarchal family. . . . Part of the charm of the ethnic image in the media is that it sanitizes patriarchy: male dominance is acceptable when it is ethnic. (221)

Yet Italian women are not the pasta-packing mamas of the media/Moynihan image. Even among early Italian immigrants, 'many women ... had craft skills, entrepreneurial or domestic service experience, or familiarity with industrial labor' (52). Nowadays most Italian women work outside the home. Depending on generation, class, location and myriad other factors, they relate to the feminist movement in various ways. They find their own way of dealing with the social forces which have affected other women in the US (such as increased participation in the labour force) and the variously imposed, internalized, rejected and chosen definitions of what it is to be an Italian American woman.

Part of Italian women's role in social reproduction is the reproduction of ethnicity. The 'work of kinship' is not confined to impoverished women of colour (Stack, 1974), but is a typical function of women cross-cutting race, ethnicity and class. By maintaining inter-family networks, and creating the foods, festivals and family gatherings by which Italian men define their own ethnicity, Italian women reproduce Italian ethnicity. How and whether they play this role varies, however, by region, generation, their own specific relationship to production and to ethnic and gender ideologies.

Varieties of Ethnic Experience is a sophisticated analysis of the intersections of class, ethnicity, gender and race. It is both a political economy of ethnicity and gender, and a subtle and rich analysis of the processes by which ethnicity as culture and lived experience is reproduced and changed, variously, by individuals in their daily interaction with each other and the US political economy. Most important, di Leonardo is attentive to the role of racism in the social construction of ethnicity. Some of the prose is obscure, and I wish that she had drawn out some practical political implications of her work. But anyone wishing to understand ethnicity in North America should follow her explicit model for the study of immigrants and their children.

Di Leonardo's work is especially valuable precisely because, to date, work about white ethnic women has lagged far behind the work by women of colour on the intersection of race, class and gender oppression. Beginning before the Combahee River statement in 1977 (Smith 1983:272-83), and continuing on through the latest works being produced by the Center for Research on Women at Memphis State 
University (e.g. Timberlake et al., 1988), women of colour have explored the framework of their interlocking oppression, and the system which creates it. They have done so against and within a feminist movement whose cultural and political agenda has been set by 'white' middle-class women. Their work, and di Leonardo's, has questioned the meaning and presumptions of whiteness, and the nature, direction, and definition of US feminism.

Unfortunately Winston Van Horne's anthology, Ethnicity and Women, seems to have been produced far from this burgeoning and exciting political and scholarly work. Ethnicity and Women is the fifth volume in the Ethnicity and Public Policy series. The series began with a concern about the 'inclusiveness or exclusiveness' of American society with respect to racial and ethnic minorities. Nathan Glazer wrote one of the two lead articles of the inaugural volume. The committee publishing the series is all male; most of the earlier authors were male, and Ethnicity and Women appears to be the editor's attempt to include women into his ethnic series as he wishes to promote the inclusion of 'ethnic' women into the American polity. Taking his theme from Plato, the editor, in an introduction co-authored by Toni-Michelle Travis, argues in favour of encouraging qualified women to 'keep watch over the home [and] over the commonwealth as well'.

Against the grain of the Reagan era, a book providing empirical backing for affirmative action and for the inclusion of women of colour in the political process has some merit. Hopefully it will bring to an audience of political scientists and policy-makers materials which they would otherwise never see, given the ghettoization of feminist writings. Hopefully it will also help alert white feminism to the problem of racism within the women's movement. The empirical data presented in Ethnicity and Women may be useful for teaching and political action. The authors' discussions of differences of ethnicity, culture and condition among women of colour help to move us beyond simplistic stereotypes of 'Black', 'Hispanic' and 'Asian' into an understanding of the varieties of racial and ethnic experience.

Despite its merits, however, the book is uneven in quality, its chief limitation being the weakness of the theoretical framework used by most of the authors to interpret their data. We need to move beyond not only the stereotypes, but the whole Glazer/Moynihan problematic of absorption and competitive assimilation which presumes - and ideologically preserves - the structure of racial, ethnic, class and gender inequality in place.

With some notable exceptions, the essays in Ethnicity and Women suffer from the framework in which they are included, and from their apparent distance from the excellent work of other feminists of colour. On the other hand, the contributors to this anthology who transcend this framework - notably Almquist, Romero, and Steinmetz and Pellicciaro, further the essential work of understanding, and combatting, race, ethnic, class and gender oppression.

In 'Further Consequences of Double Jeopardy: The Reluctant 
Participation of Racial-Ethnic Women in Feminist Organizations' (perhaps the best essay in Ethnicity and Women), Elizabeth M. Almquist adapts Robert Blauner's internal colonialism model to discuss barriers to Black women's participation in the women's movement. Internal colonialism - involving involuntary entry to the US, suppression of culture, racist ideology and the creation and institutionalization of a racial division of labor:

has overemphasized certain facets of women's roles, placed additional burdens on racial-ethnic women ... divided nonwhite and white women ideologically, and led women to subordinate their interests as women to the interests of their particular ethnic group. [It has thus] . . severely limited the resources minority women have had to commit to any social movement, [and] encouraged them to consider racial grievances as far more pressing than sexual issues. (116)

Urban racial segregation has aggravated this tendency, and the destruction of other minority institutions has 'required a defensive strengthening of the family ... [which] often translated into a need for a strong mother' (117).

Almquist argues effectively that Black women share white feminists' beliefs and ideology, particularly their emphasis on 'the right to control one's body ... to choose meaningful work and be appropriately compensated for it', but because of the structure of racism, Black women put greater priority on racial issues, 'perceive little identity with majority women' and 'question ... the prospect of free and equal participation with white women in an organized movement' (128). That is, Almquist argues, as does di Leonardo in her volume, that racism and ethnic ideology complicate, but do not destroy, minority women's relation to feminism.

Almquist's recommended strategies make sense: in view of the segregation of social and residential life, 'Workplace organizing [where women of various races work] holds high potential for increasing structural ties and for highlighting common interests. ...' In general, 'those who would like to present a united, racially integrated feminist front ... will have to mount a simultaneous assault on both racism and sexism. . . . For double jeopardy there must be double solutions'. (131)

Internal colonialism also shaped the conditions of Chicanas. Mary Romero argues that Anglo conquest of Mexican territory, expropriation of their property, and super-exploitation of their labour are the roots of their poverty and powerlessness. Comparing occupational statistics in 'Twice Protected? Assessing the Impact of Affirmative Action on Mexican-American Women', she shows that despite white men's weeping, 'reverse racism' does not exist. Rather than being 'twice protected', Chicanas are the victims of double occupational segregation and a dual wage system. Statistically, they have experienced the least upward mobility.

In view of these processes of internal colonialism and gender 
subordination, much more is needed than the integration of minority women into the existing 'American polity', and those authors in Ethnicity and Women who still search for the American Dream founder on its contradictions. Take, for example, Jeanne P. Gordus and Marian M. Oshiro's 'Ethnic-Minority Women in the Private Corporation'. Gordus and Oshiro are especially interested in 'officials and managers'. Why? Not because these might be the positions of power in American corporations, but because that is where minority women might make 'the greatest economic gains'. Despite occupational discrimination against minority women, carefully documented in their essay, Gordus and Oshiro specifically eschew 'collective action', and instead propose ways that minority women can better 'prepare themselves', as human capital, for managerial positions.

The authors recognize that corporate promotion operates on the principle: ' "I am like you, therefore I can be trusted like you"', and they recognize that, as a result, 'self-identity as a woman and as a member of one's race may be compromised' in the effort to conform to the dominant culture. But they do not challenge this WASP male ethnocentrism and discrimination. Instead, they bemoan minority women's lack of the 'corporate role models', that white women presumably have in fathers and husbands. They thereby stereotype white women, lacking a clear analysis of either class differences among white women or of corporate culture.

Despite two waves of the feminist movement, the civil rights movement, affirmative action programmes, and an influx of women and third-world men into MBA programmes, there is still not one woman (of whatever race) and not one third-world man among the top officers of the 100 largest American corporations. Even among white males, Catholics, especially Italians and Poles, are under-represented at the very top.

If WASP male managers are ethnocentric, racist and sexist, why would any women want them as 'role models'? What, after all, is the corporate 'role model'? Given the structure of capitalism-racismpatriarchy, the role of the corporate manager is to pursue those profit-seeking policies which maintain the racial and gender division of labour described by Almquist as putting women of colour in 'double jeopardy'. The corporate role is to maintain the conditions which produce the depressing statistics which Romero, and Gordus and Oshiro themselves, present. In view of the tight nexus, the interlocking directorships, among corporations, media and government, I think it is not too much to say that the corporate role also helps to maintain the general level of societal violence described by Steinmetz and Pellicciaro in 'Women, Ethnicity and Family Violence', as underpinning family abuse. It perpetuates the racist and sexist castigation of strong Black mothers, periodically manufactured by Moynihan and the media, and criticized, in this volume, by Elmer P. Martin and Joanne Mitchell Martin. Given the structural constraints - the profit imperatives which apply to all managers, regardless of ethnicity or gender, the 
question one must ask is 'what would minority women be integrating themselves into even if they were to succeed in assimilating into the top managerial roles of an unchanged American politico-economic system?' What is lacking in many of the articles in Ethnicity and Women is an understanding of the political and economic system producing the problems its authors analyze.

In 1975 Nathan Glazer leapt to the right, calling affirmative action Affirmative Discrimination (Glazer, 1975). Members of racial and ethnic minorities must seek individual rights, not group rights, he peeved. To its credit, Ethnicity and Women pushes strongly for affirmative action, despite affirmative action's limited yield to date, documented fully in this volume. In a democracy, affirmative action is the least that we can ask. But it is insufficient, both as political goal and as analysis. Affirmative action seeks equal success for those women and ethnic men who have achieved equal 'qualifications' in an unequal system. As analysis and as programme it leaves out the context, the class, racial, ethnic, patriarchal structure which defines those qualifications, creates those inequalities, and frames the electoral and social processes described in this book. Despite the reactionary road both Glazer and Moynihan have travelled since 1963, affirmative action remains within the more liberal problematic of the pseudo-pluralism they originally defined, and shares the limitations of that framework.

I keep thinking of the political badge I used to see: 'Women who only seek equality with men lack imagination'. In envisioning the varieties of women's ethnic experience, in tracing the structure and process of class, ethnic, race and gender relations, we can begin to dismantle the master's house (Lorde, 1984) and imagine our future.

\section{References}

GLAZER, Nathan (1975) Affirmative Discrimination: Ethnic Inequality and Public Policy, New York: Basic Books.

GLAZER, Nathan and MOYNIHAN, Daniel Patrick (1963) Beyond the Melting Pot, Cambridge, Mass.: The MIT Press.

LORDE, Audre (1984) 'The Master's Tools Will Never Dismantle the Master's House' in Sister Outside, Trumansberg, New York: The Crossing Press.

SMITH, Barbara editor (1983) Homegirls: A Black Feminist Anthology, New York: Kitchen Table/Women of Colour Press.

STACK, Carol (1974) All Our Kin: Strategies for Survival in a Black Community, New York: Harper and Row.

TIMBERLAKE, Andrea, CANNON, Lynn Weber, GUY, Rebecca F. and HIGGENBOTHAM, Elizabeth (1988) Women of Color and Southern Women: A Bibliography of Social Science Research, Memphis: Center for Research on Women, Memphis State University. 